\title{
Measurement on Diffusion Coefficients and Isotope Fractionation Factors by a Through-Diffusion Experiment
}

\author{
Takuma Hasegawa ${ }^{1, *}$, Kotaro Nakata $^{1}$ and Rhys Gwynne ${ }^{2}$ \\ 1 Civil Engineering Research Laboratory, Central Research Institute of Electric Power Industry, Abiko, \\ Chiba 270-1194, Japan; k-nakata@criepi.denken.or.jp \\ 2 Environmental Isotope Laboratory, University of Waterloo, Waterloo, ON N2L 3W8, Canada; \\ rgwynne@uwaterloo.ca \\ * Correspondence: t-hase@criepi.denken.or.jp
}

Citation: Hasegawa, T.; Nakata, K.; Gwynne, R. Measurement on Diffusion Coefficients and Isotope Fractionation Factors by a Through-Diffusion Experiment. Minerals 2021, 11, 208. https:// doi.org/10.3390/min11020208

Academic Editor: Hans Eggenkamp Received: 17 December 2020

Accepted: 9 February 2021

Published: 16 February 2021

Publisher's Note: MDPI stays neutral with regard to jurisdictional claims in published maps and institutional affiliations.

Copyright: (c) 2021 by the authors. Licensee MDPI, Basel, Switzerland. This article is an open access article distributed under the terms and conditions of the Creative Commons Attribution (CC BY) license (https:// creativecommons.org/licenses/by/ $4.0 /)$.
Abstract: For radioactive waste disposal, it is important that local groundwater flow is slow as groundwater flow is the main transport medium for radioactive nuclides in geological formations. When the groundwater flow is very slow, diffusion is the dominant transport mechanism (diffusiondominant domain). Key pieces of evidence indicating a diffusion-dominant domain are the separation of components and the fractionation of isotopes by diffusion. To prove this, it is necessary to investigate the different diffusion coefficients for each component and the related stable isotope fractionation factors. Thus, in this study, through-diffusion and effective-porosity experiments were conducted on selected artificial materials and natural rocks. We also undertook measurements relating to the isotope fractionation factors of $\mathrm{Cl}$ and $\mathrm{Br}$ isotopes for natural samples. For natural rock samples, the diffusion coefficients of water isotopes ( $\mathrm{HDO}$ and $\mathrm{H}_{2}{ }^{18} \mathrm{O}$ ) were three to four times higher than those of monovalent anions $\left(\mathrm{Cl}^{-}, \mathrm{Br}^{-}\right.$and $\left.\mathrm{NO}_{3}{ }^{-}\right)$, and the isotope fractionation factor of ${ }^{37} \mathrm{Cl}$ (1.0017-1.0021) was slightly higher than that of free water. It was experimentally confirmed that the isotope fractionation factor of ${ }^{81} \mathrm{Br}$ was approximately $1.0007-1.0010$, which is equivalent to that of free water. The enrichment factor of ${ }^{81} \mathrm{Br}$ was almost half that of ${ }^{37} \mathrm{Cl}$. The effective porosity ratios of $\mathrm{HDO}$ and $\mathrm{Cl}$ were slightly different, but the difference was not significant compared to the ratio of their diffusion coefficients. As a result, component separation was dominated by diffusion. For artificial samples, the diffusion coefficients and effective porosities of $\mathrm{HDO}$ and $\mathrm{Cl}$ were almost the same; it was thus difficult to assess the component separation by diffusion. However, isotope fractionation of $\mathrm{Cl}$ and $\mathrm{Br}$ was confirmed using a through-diffusion experiment. The results show that $\mathrm{HDO}$ and $\mathrm{Cl}$ separation and isotope fractionation of $\mathrm{Cl}$ and $\mathrm{Br}$ can be expected in diffusion-dominant domains in geological formations.

Keywords: diffusion-dominant; ${ }^{37} \mathrm{Cl} ;{ }^{81} \mathrm{Br}$; isotope fractionation; component separation

\section{Introduction}

Diffusion is the slowest transport mechanism in a geological formation. For this reason, in diffusion-dominant systems, groundwater flow is very slow and solute transport is limited. In general, the ratio between advection and diffusion is characterized by the Peclet number (=vL/D: $\mathrm{v}$ is velocity, $\mathrm{L}$ is the characteristic length, $\mathrm{D}$ is the diffusion coefficient); diffusion is dominant when the Peclet number is below one. Exploitation of diffusion-dominant domains is considered to be promising for radioactive waste disposal. Therefore, many studies have evaluated diffusion-dominant domains in natural systems. These studies have been summarized [1-3].

In this study, diffusion experiments were conducted to investigate component separation and isotope fractionation by diffusion. The diffusion coefficients of HDO and $\mathrm{Cl}$ in free water were investigated [4,5]. The diffusion coefficients of $\mathrm{HDO}$ and $\mathrm{Cl}$ were similar to that of free water. However, in natural rocks, the diffusion coefficient of HDO was about three times higher than those of anions such as $\mathrm{Cl}^{-}$and $\mathrm{Br}^{-}$. This was due to interactions 
of the anions with negatively charged clay surfaces, which influence the anionic diffusion [2]. Anions are typically restricted to passing thorough pores by diffusion. By using this difference, the diffusion time and boundary condition changes was discussed [6-8].

$\mathrm{Cl}$ isotopes are fractionated by diffusion; therefore, $\delta^{37} \mathrm{Cl}$ is an important tool for the identification of a diffusion-dominant domain. Many studies have attempted to use isotope fractionation to estimate the diffusion time and boundary condition changes [9-13].

A combination of component separation and isotope fractionation is the most promising method to determine whether a system is diffusion-dominant. In Japan, it is common to find that marine sedimentary rock has been uplifted and flushed by meteoric water. This is a suitable condition under which to assess diffusion-dominant domains in which both component separation and isotope fractionation occur, as normally there is a large difference in $\mathrm{HDO}$ and $\mathrm{Cl}$ between seawater and meteoric water.

In this study, diffusion experiments were conducted with artificial and natural samples to measure the diffusion coefficients of $\mathrm{HDO}, \mathrm{Cl}$ and $\mathrm{Br}$, as well as the isotope fractionation factors of ${ }^{37} \mathrm{Cl}$ and ${ }^{81} \mathrm{Br}$. This was the first attempt to determine $\mathrm{Br}$ isotope fractionation factors by diffusion for natural rocks in a laboratory. Effective porosity for each component was also measured. Effective porosity influences the progress of diffusion, which depends on $D_{e} / n_{e}$, where $D_{e}$ is the effective diffusion coefficient and $n_{e}$ is the effective porosity. If $\mathrm{D}_{\mathrm{e}} / \mathrm{n}_{\mathrm{e}}$ is the same for $\mathrm{HDO}$ and $\mathrm{Cl}$, component separation does not occur. Therefore, effective porosity was also measured to estimate the progress of diffusion.

\section{Experimental Method}

\subsection{Samples}

Porous stone, glass filters, and ceramic disks were used as the artificial samples. For the natural samples, the sedimentary rock of the confined layer of the Great Artesian Basin in Australia and siliceous mudstone from Horonobe in the north of Japan were used.

The artificial samples used were various types of filter for soil tests: the glass filters were sintered glass beads, and the porous stones and ceramic disks were sintered clay particles. The porous stones and glass filters were also bound to natural samples to prevent them from collapsing. Ceramic disks are normally used for soil testing. They are categorized by air entry value, which relates to pore radius. Here, air entry values of $1,3,5$, and 15 Bar were used.

The confined layer of the Great Artesian Basin was from Richmond and Marree, which are the recharge and discharge areas of the Great Artesian Basin, respectively, that were previously drilled and cored [13]. These belong to the Rolling Down Group and are categorized as mudstone [14]. The formation at Richmond is more consolidated compared to Marree. The porosities of Richmond and Marree are about $25 \%$ and $40 \%$, respectively.

The Horonobe siliceous mudstone that was used was from the Koetoi and Wakkanai Formation. The difference between these two geological formations lies in the diagenesis of the mudstone [15]. The Koetoi Formation has not undergone diagenesis, is mainly composed of Opal-A, and has a high porosity ratio of about $60 \%$. The Wakkanai Formation has undergone diagenesis, is mainly composed of Opal-CT, and has a lower porosity ratio of about $40 \%$ relative to the Koetoi Formation. These rocks were sampled from the Horonobe Underground Research Laboratory (URL). The boundary between the Wakkanai and Koetoi Formations is at a depth of about $250 \mathrm{~m}$ in the Horonobe URL.

\subsection{Through-Diffusion Experiment}

A through-diffusion experiment was conducted as shown in Figure 1 [16]. The purpose of the experiment was to determine the diffusion coefficients for $\mathrm{HDO}, \mathrm{Cl}$, and $\mathrm{Br}$ and the fractionation factors for the $\mathrm{Cl}$ and $\mathrm{Br}$ isotopes. Occasionally, samples of sedimentary rocks crack due to swelling and unloading. In these cases, advection occurs due to densitydependent flow between the low- and high-concentration tanks, and the diffusion flux may be overestimated due to advection. Thus, reverse direction diffusion from the low- to high-concentration tank was also measured. In the experiment, the high-concentration tank 
contained $\mathrm{HDO}, \mathrm{Cl}, \mathrm{Br}$, and NAP. NAP is a fluorescent dye-1-Naphthylamine-4-sulfonic Acid Sodium Salt Tetrahydrate. The low-concentration tank contained $\mathrm{Na}, \mathrm{NO}_{3}$, and $\delta^{18} \mathrm{O}$. $\mathrm{NaNO}_{3}$ solution was used for the desalinization of rock samples, which was necessary as they contained high $\mathrm{NaCl}$ contents in their core. The concentrations of the high- and low-concentration tanks are shown in Table 1.

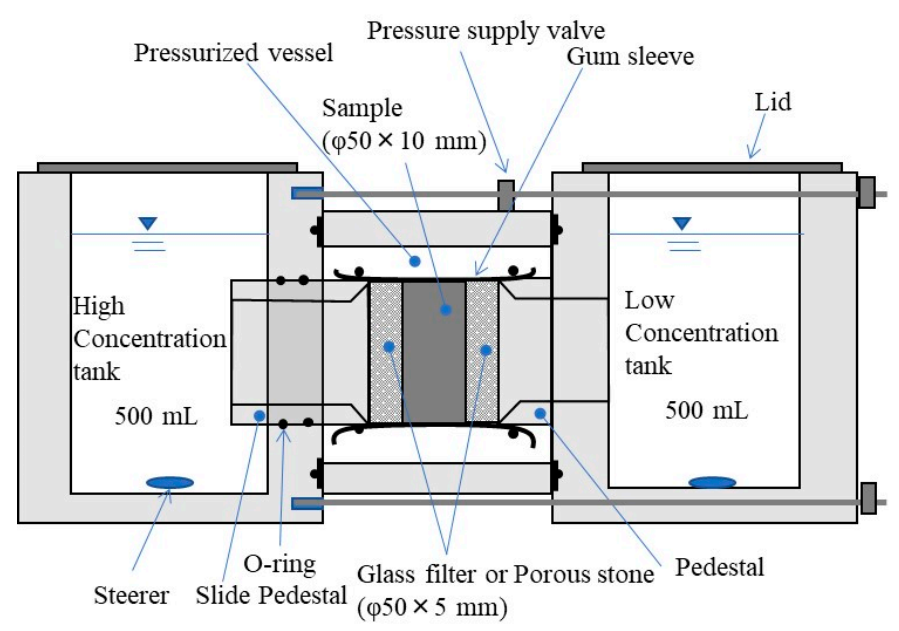

Figure 1. Systematic view of through-diffusion experiment.

Table 1. Tracers used for through-diffusion experiment.

\begin{tabular}{|c|c|c|c|}
\hline Tracer & Unit & High & Low \\
\hline HDO & $\delta^{2} \mathrm{H}(\% \mathrm{VSMOW})$ & 23,000 & -65 \\
\hline $\mathrm{H}_{2}{ }^{18} \mathrm{O}$ & $\delta^{18} \mathrm{O}(\% \circ \mathrm{VSMOW})$ & -13.2 & 1000 \\
\hline $\mathrm{Na}$ & \multirow{7}{*}{$\mathrm{mg} / \mathrm{L}$} & 0 & 28,000 \\
\hline $\mathrm{NO}_{3}$ & & 0 & 74,000 \\
\hline $\mathrm{Sr}$ & & 29,000 & 0 \\
\hline $\mathrm{Cl}$ & & 24,000 & 0 \\
\hline Cs & & 8300 & 0 \\
\hline $\mathrm{Br}$ & & 5000 & 0 \\
\hline NAP & & 10 & 0 \\
\hline
\end{tabular}

The through-diffusion experiment was successful when the diffusion coefficients of $\delta^{18} \mathrm{O}$ and $\mathrm{NO}^{3-}$ were in agreement with those of $\mathrm{HDO}$ and the anions $\left(\mathrm{Cl}^{-}\right.$and $\left.\mathrm{Br}^{-}\right)$. The ceramic disks were the same as the samples tested [16]. Porous and glass filters have high conductivity and ager gel was thus used to prevent advective flow [17]. Sedimentary rock may become cracked by swelling. The sedimentary rock samples were thus bound by porous stones or porous glass for structural support, and the high-concentration solutions (Table 1) were used to prevent swelling.

The through-diffusion experiment was conducted as follows:

(1) Form sample to dimensions of about $\varphi 50 \mathrm{~mm} \times \mathrm{H} 10 \mathrm{~mm}$.

(2) Desalinization; dip the sample into $\mathrm{NaNO}_{3}$ solution.

(3) Set the sample on the apparatus shown in Figure 1.

(4) Pour $500 \mathrm{~mL}$ of background solution into the low-concentration tank and check that there is no flow.

(5) Pour $500 \mathrm{~mL}$ of tracer into the high-concentration tank.

(6) Sample $2 \mathrm{~mL}$ of solution from the low- and high-concentration tanks every few days.

(7) Increase the amount of sampling solution to $20 \mathrm{~mL}$ for isotope measurement when the $\mathrm{Cl}$ concentration is higher than a few hundred $\mathrm{mg} / \mathrm{L}$. 
(8) End the experiment after taking samples approximately ten times.

Step 2 took about four weeks and was repeated two or three times to confirm the low $\mathrm{Cl}$ concentrations. Step 4 was performed to check for cracking by establishing if a flow was present. Step 7 was to measure $\mathrm{Cl}$ isotopes, which require at least $3 \mathrm{mg} \mathrm{Cl}$.

\subsection{Effective Porosity Experiment}

Effective porosity $\left(n_{e}\right)$ is a measure of the accessible porosity of each component, such as $\mathrm{HDO}, \mathrm{Cl}, \mathrm{Br}$, and NAP [2]. $\mathrm{HDO}$ can propagate better than $\mathrm{Cl}$ because clay surfaces are normally negatively charged and influence the progress of diffusion of negatively charged ions. Therefore, it is important to determine the effective porosity.

The effective porosity experiment was conducted as follows:

(1) Dip the sample into the high-concentration solution containing $\mathrm{HDO}, \mathrm{Cl}, \mathrm{Br}$, and NAP.

(2) Sample from the high-concentration solution after the concentration stabilizes.

(3) Remove the sample and dip it into the low-concentration solution

(4) Sample from the low-concentration solution after the concentration stabilizes.

(5) Remove the sample and measure its weight when saturated.

(6) Dry the sample in an oven at $110^{\circ} \mathrm{C}$ for $24 \mathrm{~h}$ and measure the dry weight.

The effective porosity was calculated as follows:

$$
\begin{gathered}
V_{C}=\frac{V_{L} C_{L}}{C_{H}-C_{L}} \\
n_{e}=\frac{V_{C}}{V_{S}}
\end{gathered}
$$

where $V_{C}$ is the pore volume of each component, $V_{L}$ is the solution volume for the low-concentration solution, and $C_{H}$ and $C_{L}$ are the concentrations of the high- and lowconcentration solutions at Steps 2 and 4, respectively. $n_{e}$ is the effective porosity, and $V_{S}$ is the volume of the sample, which can be calculated from the diameter and width.

\subsection{Measurements}

In this study, $\mathrm{HDO}(\delta \mathrm{D}), \mathrm{H}_{2}{ }^{18} \mathrm{O}\left(\delta^{18} \mathrm{O}\right), \mathrm{Na}, \mathrm{Cl}, \mathrm{Br}, \mathrm{NO}_{3}, \mathrm{NAP}, \delta^{37} \mathrm{Cl}$, and $\delta^{81} \mathrm{Br}$ were measured.

$\delta \mathrm{D}$ and $\delta^{18} \mathrm{O}$ were determined using cavity ring down spectroscopy (Los Gatos Research, San Jose, CA, USA). The $\mathrm{Na}^{+}, \mathrm{Cl}^{-}$, and $\mathrm{NO}_{3}$ concentrations were determined using ion chromatography (Metrohm Co., Herisau, Switzerland). Inductively coupled plasma mass spectrometry (ICP-MS) was used to determine $\mathrm{Br}^{-}$content (Agilent Technology, California, US). NAP was determined by fluorescence spectrophotometry (Nihonbunko, Tokyo, Japan).

$\delta^{37} \mathrm{Cl}$ and $\delta^{81} \mathrm{Br}$ were determined by gas chromatography continuous flow isotope ratio mass spectrometry (GC-CF-IRMS) at the University of Waterloo [18,19] (Agilent Technologies Inc., Santa Clara, CA, USA; Thermo Fisher Scientific, Bremen, Germany). These measurements required at least $3 \mathrm{mg}$ of $\mathrm{Cl}$ and $\mathrm{Br}$, respectively.

\section{Experimental Results}

\subsection{Through-Diffusion Experiment}

Figures 2 and 3 show the results of the through-diffusion experiments for artificial samples and natural samples, respectively. The upper figure shows concentration change and lower figure shows isotope ratio change. 


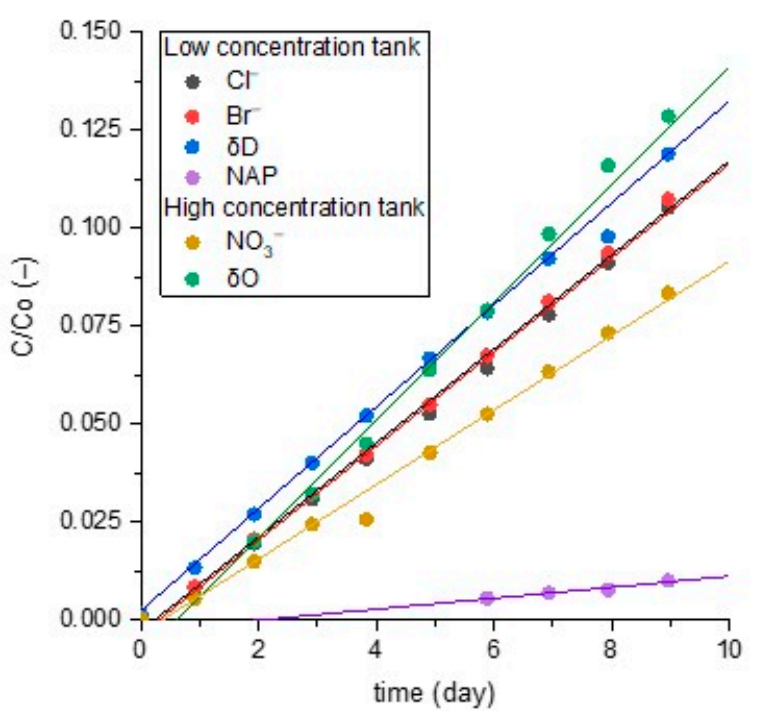

(a) Concentration change

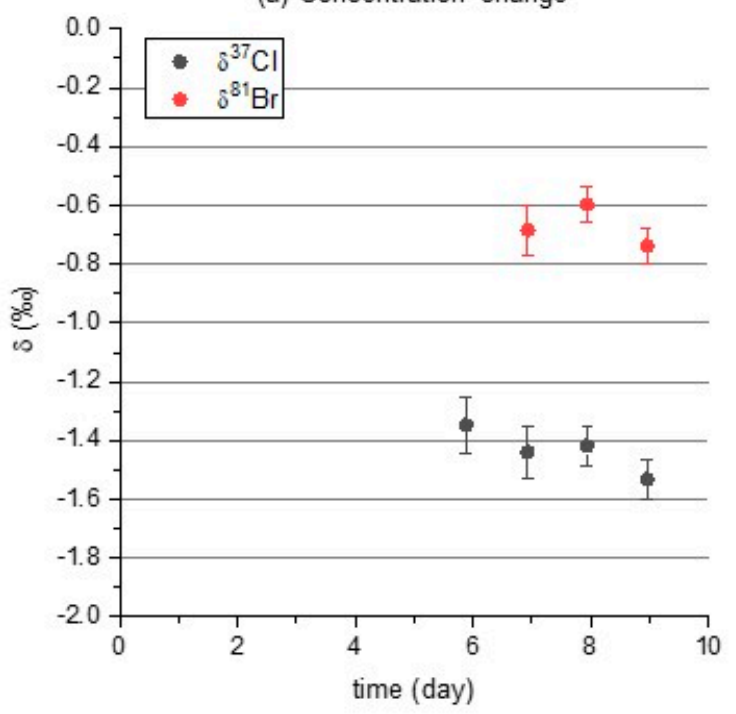

(b) Isotope ratio change

(1) Glass filter No.1

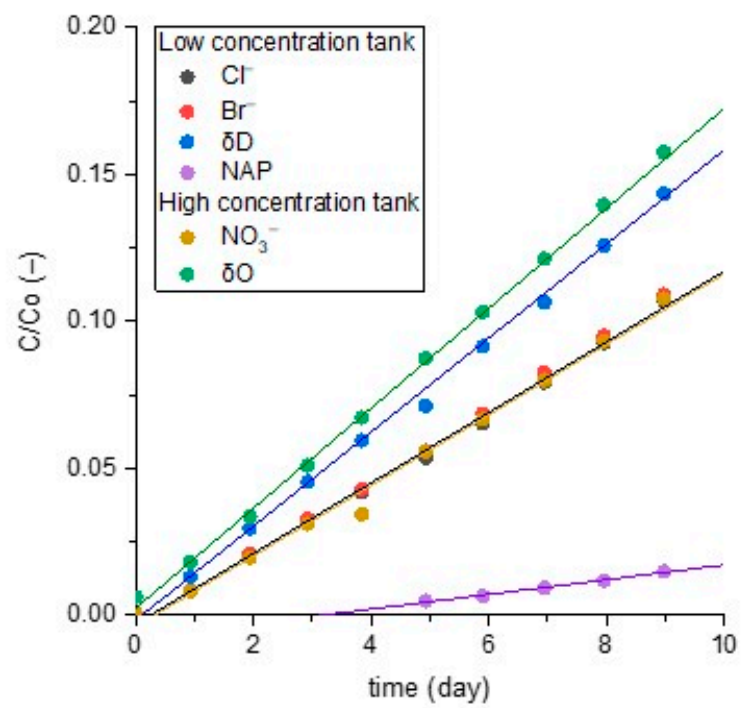

(a) Concentration change

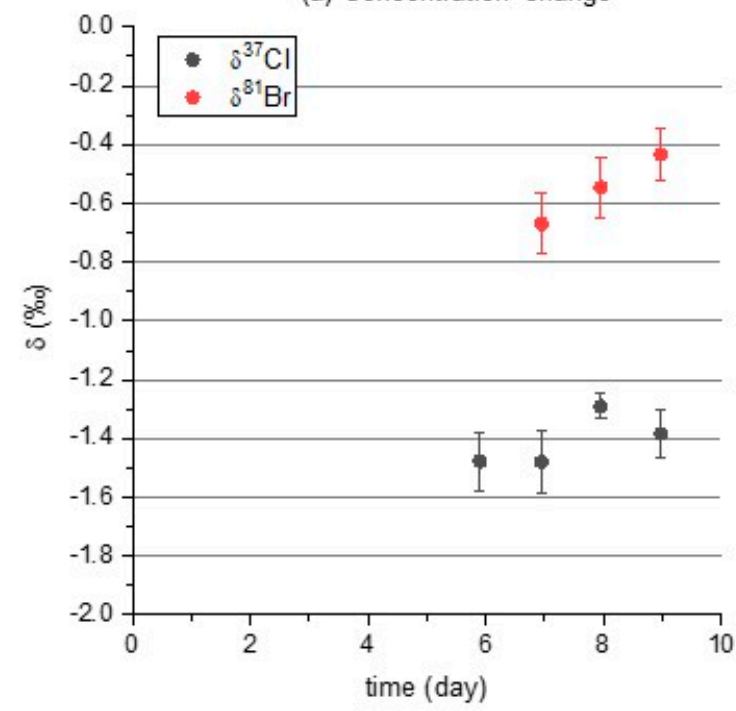

(b) Isotope ratio change

(2) Porous stone No.1

Figure 2. Results of through-diffusion experiment for artificial samples for (1) glass filter No.1 and (2) porous stone No.1, (a) concentration change, (b) isotope ratio change, $\delta$ is the difference in the isotope ratio between initial and time series measurements $\left(\delta=\delta_{t=t i m e}-\delta_{t=0}\right)$. The absolute value of $\delta$ provides the enrichment factor $((\alpha-1) \times 1000 \%)$ if the concentration change effect is neglected.

The results of the through-diffusion experiment are shown in Table 2. The ratios of the diffusion coefficients and isotope fractionation factors are shown in Table 3. The following equation, which transforms the solution for cumulative flux under constrained concentration boundaries [16,20] (pp. 49-53), was used to evaluate the diffusion coefficient:

$$
C_{L, t}=\frac{C_{H, 0} A W}{V}\left[\frac{D_{e} t}{W^{2}}-\frac{n_{e}}{6}-\frac{2 n_{e}}{\pi^{2}} \sum_{n=1}^{\infty} \frac{(-1)^{n}}{n^{2}} \exp \left(-\frac{D_{e} n_{e} n^{2} \pi^{2} t}{W^{2}}\right)\right]
$$

where $C_{L, t}$ is the concentration in the low-concentration tank at $t, t$ is time, $C_{H, 0}$ is the initial concentration in the high-concentration tank, $A$ is the cross-section area in the diffusion 
direction of sample, $W$ is the sample width, $n_{e}$ is the effective porosity, and $V$ is the tank volume. The following approximation can be applied when $D_{e} t / n_{e} L^{2}>0.45$ [20] (pp. 49-53):

$$
C_{L, t}=\frac{C_{H} A W}{V}\left[\frac{D_{e} t}{W^{2}}-\frac{n_{e}}{6}\right]
$$

The diffusion coefficient can be calculated from the relationship between time and $C_{L, t}$ as follows:

$$
D_{e}=\frac{s V W}{C_{H} A}
$$

where $\mathrm{s}$ is the slope between $C_{L, t}$ and $t$.

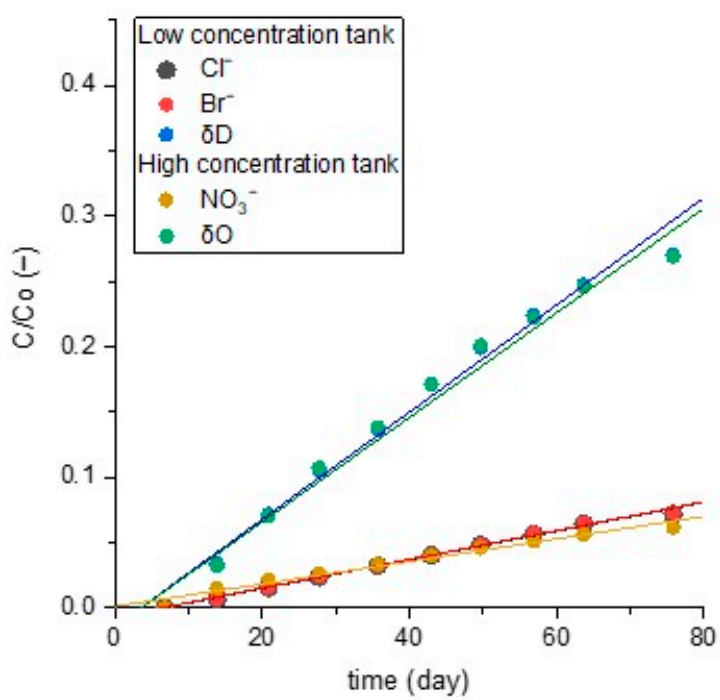

(a) Concentration change

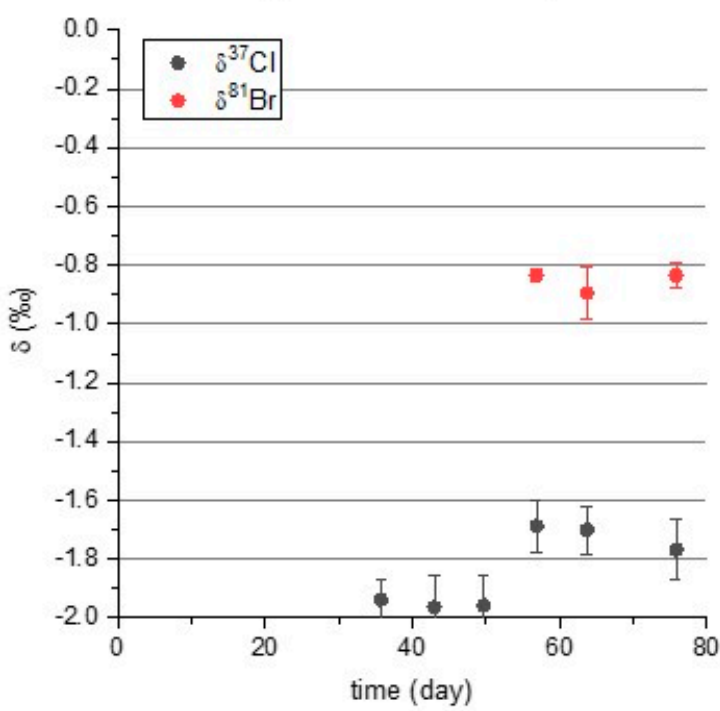

(b) Isotope ratio change

(1) Horonobe URL 350 m

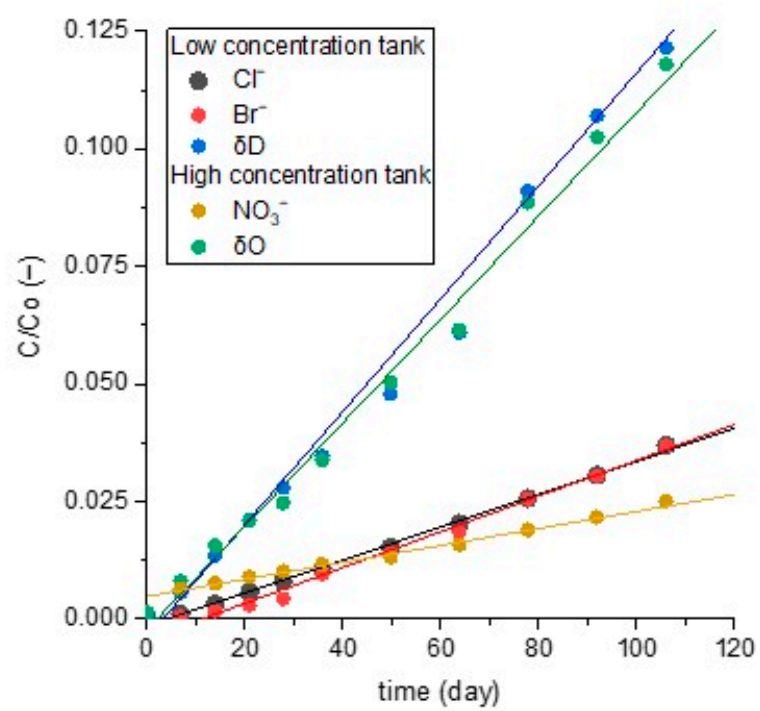

(a) Concentration change

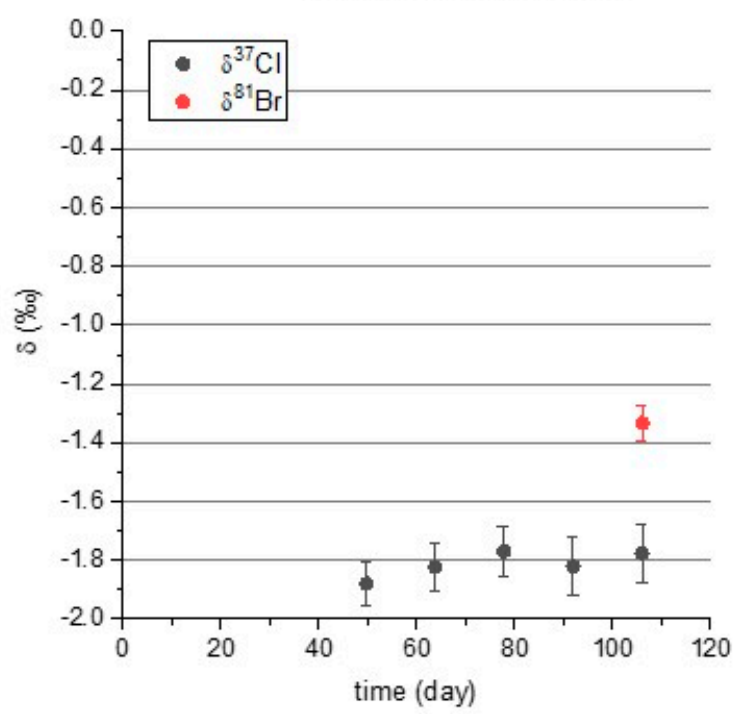

(b) Isotope ratio change

(2) Richmond 74 m

Figure 3. Results of through-diffusion experiment for natural samples or (1) Horonobe URL $350 \mathrm{~m}$ and (2) Richmond $74 \mathrm{~m}$, (a) concentration change, (b) isotope ratio change. $\delta$ is the difference in the isotope ratio between initial and time series measurements $\left(\delta=\delta_{\mathrm{t}=\text { time }}-\delta_{\mathrm{t}=0}\right)$. The absolute value of $\delta$ provides the enrichment factor $((\alpha-1) \times 1000 \%)$ if the concentration change effect is neglected. 
Table 2. Diffusion coefficient and fractionation factor by through-diffusion experiment.

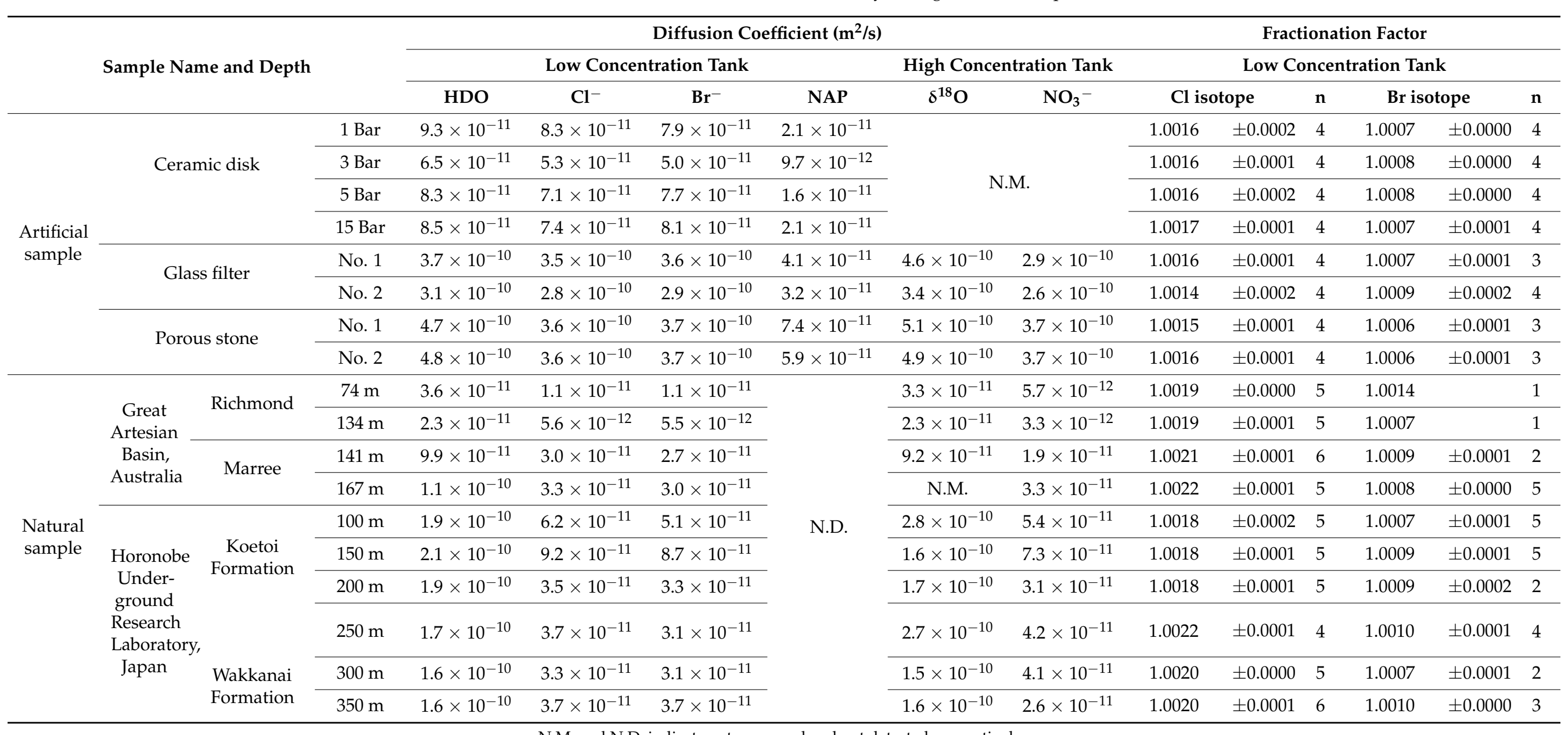


Table 3. Ratios of the diffusion coefficients and isotope enrichment factors.

\begin{tabular}{|c|c|c|c|c|c|c|c|c|c|}
\hline \multicolumn{4}{|c|}{ Sample Name and Depth } & $\mathrm{Cl}^{-*}$ & $\mathrm{Br}^{-*}$ & NAP * & $\delta^{18} O^{*}$ & $\mathrm{NO}_{3}{ }^{-*}$ & $\beta^{* *}$ \\
\hline \multirow{8}{*}{$\begin{array}{l}\text { Artificial } \\
\text { sample }\end{array}$} & \multirow{4}{*}{\multicolumn{2}{|c|}{ Ceramic disk }} & $1 \mathrm{Bar}$ & 0.89 & 0.85 & 0.23 & \multirow{4}{*}{\multicolumn{2}{|c|}{ N.M. }} & 0.46 \\
\hline & & & $3 \mathrm{Bar}$ & 0.81 & 0.77 & 0.15 & & & 0.47 \\
\hline & & & 5 Bar & 0.86 & 0.93 & 0.20 & & & 0.52 \\
\hline & & & 15 Bar & 0.88 & 0.96 & 0.25 & & & 0.42 \\
\hline & \multirow{2}{*}{\multicolumn{2}{|c|}{ Glass filter }} & No.1 & 0.94 & 0.96 & 0.11 & 1.24 & 0.77 & 0.47 \\
\hline & & & No.2 & 0.90 & 0.93 & 0.10 & 1.07 & 0.82 & 0.68 \\
\hline & \multirow{2}{*}{\multicolumn{2}{|c|}{ Porous stone }} & No.1 & 0.76 & 0.78 & 0.16 & 1.09 & 0.78 & 0.39 \\
\hline & & & No.2 & 0.75 & 0.77 & 0.13 & 1.02 & 0.78 & 0.39 \\
\hline \multirow{10}{*}{$\begin{array}{l}\text { Natural } \\
\text { sample }\end{array}$} & \multirow{4}{*}{$\begin{array}{l}\text { Great Artesian } \\
\text { Basin, Australia }\end{array}$} & \multirow{2}{*}{ Richmond } & $74 \mathrm{~m}$ & 0.29 & 0.31 & \multirow{10}{*}{ N.D. } & 0.91 & 0.16 & 0.75 \\
\hline & & & $134 \mathrm{~m}$ & 0.24 & 0.24 & & 1.01 & 0.15 & 0.37 \\
\hline & & \multirow{2}{*}{ Marree } & $141 \mathrm{~m}$ & 0.30 & 0.28 & & 0.93 & 0.19 & 0.41 \\
\hline & & & $167 \mathrm{~m}$ & 0.30 & 0.28 & & 0.00 & 0.31 & 0.37 \\
\hline & \multirow{6}{*}{$\begin{array}{l}\text { Horonobe } \\
\text { Underground } \\
\text { Research } \\
\text { Laboratory, } \\
\text { Japan }\end{array}$} & \multirow{4}{*}{ Koetoi Formation } & $100 \mathrm{~m}$ & 0.33 & 0.27 & & 1.51 & 0.29 & 0.41 \\
\hline & & & $150 \mathrm{~m}$ & 0.44 & 0.42 & & 0.76 & 0.35 & 0.50 \\
\hline & & & $200 \mathrm{~m}$ & 0.18 & 0.17 & & 0.88 & 0.16 & 0.51 \\
\hline & & & $250 \mathrm{~m}$ & 0.22 & 0.18 & & 1.56 & 0.25 & 0.46 \\
\hline & & \multirow{2}{*}{ Wakkanai Formation } & $300 \mathrm{~m}$ & 0.20 & 0.20 & & 0.94 & 0.26 & 0.35 \\
\hline & & & $350 \mathrm{~m}$ & 0.23 & 0.23 & & 0.98 & 0.16 & 0.48 \\
\hline
\end{tabular}

* The diffusion coefficient was divided by the diffusion coefficient of HDO. ${ }^{* *} \beta$ (raito of isotope enrichment factor) was calculated as $\left(\alpha_{\mathrm{Br}}-1\right) /\left(\alpha_{\mathrm{Cl}}-1\right)$. N.M. and N.D. indicate not measured and not detected, respectively.

For the ceramic discs, the diffusion coefficients were $6.5-9.3 \times 10^{-11} \mathrm{~m}^{2} / \mathrm{s}$ for HDO, $5.0-8.3 \times 10^{-11} \mathrm{~m}^{2} / \mathrm{s}$ for $\mathrm{Cl}$ and $\mathrm{Br}$, and $0.97-2.1 \times 10^{-11} \mathrm{~m}^{2} / \mathrm{s}$ for NAP.

For the glass filters and porous stone, the diffusion coefficients were $3.1-4.8 \times 10^{-10}$ $\mathrm{m}^{2} / \mathrm{s}$ for HDO, $2.8-3.7 \times 10^{-10} \mathrm{~m}^{2} / \mathrm{s}$ for $\mathrm{Cl}$ and $\mathrm{Br}$, and $3.2-7.4 \times 10^{-11} \mathrm{~m}^{2} / \mathrm{s}$ for NAP.

For the artificial samples, the diffusion coefficients of $\mathrm{HDO}$ and the anions $(\mathrm{Cl}$ and $\mathrm{Br})$ were almost the same, as shown in Table 3 in which the ratio of the diffusion coefficient normalized by the diffusion coefficient for HDO is provided. The diffusion coefficient of NAP was $10-30 \%$ of the other components.

For the natural samples, the diffusion coefficient derived from Equation (5) should be corrected to account for the bound porous stone and porous glass. The correction methods will be discussed below.

For the Richmond samples, the diffusion coefficients were $2.3-3.6 \times 10^{-11} \mathrm{~m}^{2} / \mathrm{s}$ for $\mathrm{HDO}$ and $0.56-1.1 \times 10^{-11} \mathrm{~m}^{2} / \mathrm{s}$ for $\mathrm{Cl}$ and $\mathrm{Br}$. For the Marree samples, the diffusion coefficients were $0.99-1.1 \times 10^{-10} \mathrm{~m}^{2} / \mathrm{s}$ for HDO and $2.7-3.3 \times 10^{-11} \mathrm{~m}^{2} / \mathrm{s}$ for $\mathrm{Cl}$ and $\mathrm{Br}$. The diffusion coefficient of Richmond was smaller than that of Marree due to the higher porosity of Marree. The diffusion coefficient of HDO was three to four times higher than those of the anions. The diffusion coefficient of NAP could not be estimated because NAP could not be detected in the low-concentration tank.

For the Horonobe samples, the diffusion coefficients were $1.6-2.1 \times 10^{-10} \mathrm{~m}^{2} / \mathrm{s}$ for HDO, and 3.1-9.2 $\times 10^{-11} \mathrm{~m}^{2} / \mathrm{s}$ for $\mathrm{Cl}$ and Br. The diffusion coefficient of HDO was similar for all Horonobe samples. On the contrary, the diffusion coefficients of the Koetoi Formation for $\mathrm{Cl}$ and $\mathrm{Br}$ were slightly larger than those of the Wakkanai Formation. The diffusion coefficient of HDO was two to five times higher than those of the anions. The diffusion coefficient of NAP could not be estimated, as mentioned before. 


\subsection{Effective Porosity Experiment}

The results of the effective porosity experiments are shown in Table 4. This table shows the effective porosities for $\mathrm{HDO}, \mathrm{Cl}, \mathrm{Br}$, and NAP and the porosities determined with the drying method. The ratios of the porosities divided by the drying porosities are also shown in Table 4.

Table 4. Porosity derived by solute and drying; porosity ratio divided by drying porosity.

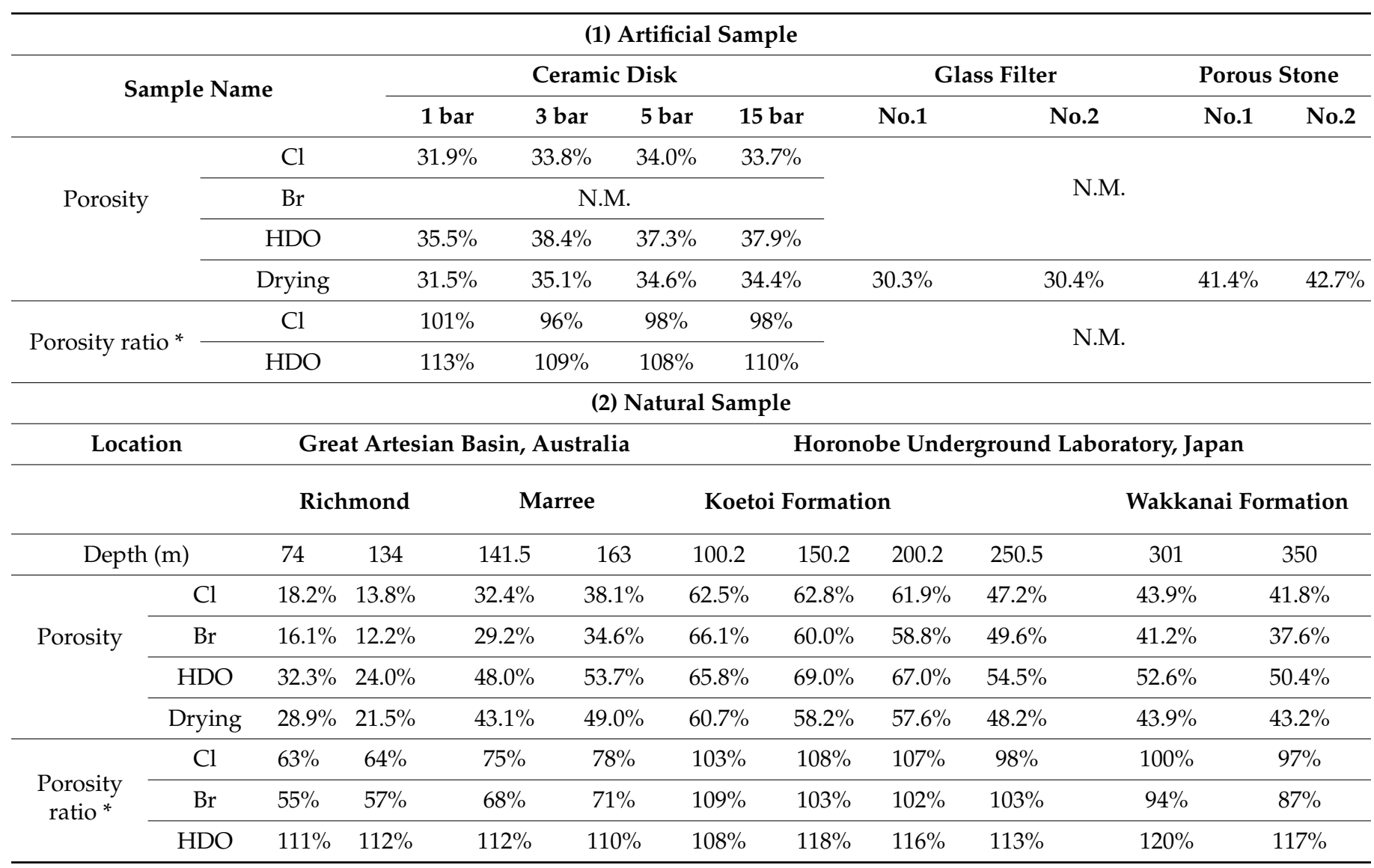

* The porosity ratio was calculated by dividing the porosity by the drying porosity.

For the artificial samples, the porosity of $\mathrm{HDO}$ was slightly higher than that of $\mathrm{Cl}$ but within $12 \%$, so the porosities of $\mathrm{HDO}$ and $\mathrm{Cl}$ can be considered to be similar. In contrast, for the Richmond and Marree samples, the porosity ratios of $\mathrm{Cl}$ and $\mathrm{HDO}$ were about $50 \%$ and $70 \%$, respectively. For the Horonobe samples, it was $80-100 \%$. The decreasing ratio was smaller than those for Richmond and Marree.

\section{Discussion}

\subsection{Corrections for Natural Samples Bound by Porous Stone and Glass Filters}

Natural samples were bound by porous stones or glass filters to prevent cracking by swelling and unloading. Ceramic discs, glass filters, and porous stones were set onto the pedestal directly, without additional support. Thus, a correction had to be applied to accurately estimate the diffusion coefficients for natural rocks.

Assuming a conceptual model of bound samples as shown in Figure 4, under a steady state, the relationship between flux and the diffusion coefficient is expressed as follows:

$$
\begin{gathered}
F=D_{1} \frac{\Delta C_{1}}{\Delta L_{1}}=D_{2} \frac{\Delta C_{2}}{\Delta L_{2}}=D_{3} \frac{\Delta C_{3}}{\Delta L_{3}} \\
\Delta C=\Delta C_{1}+\Delta C_{2}+\Delta C_{3}
\end{gathered}
$$


where $F$ is flux, $D_{i}$ is the diffusion coefficient of the $i$-th material, $\Delta C_{i}$ is the concentration difference within the $i$-th material, and $\Delta L_{i}$ is the length of the $i$-th material.

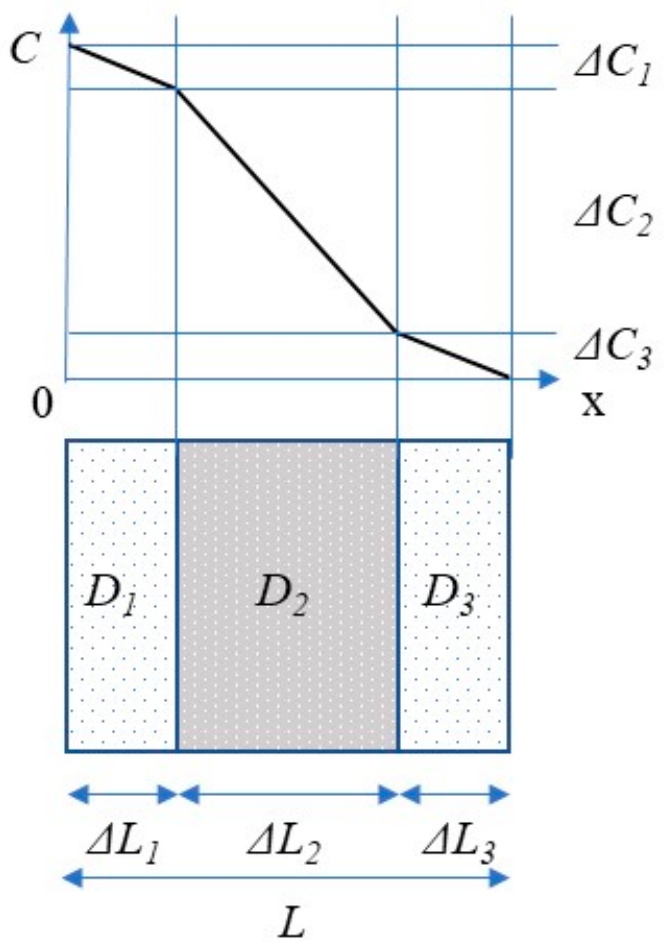

Figure 4. Conceptual model of bound sample.

Considering the experimental condition, $D_{1}=D_{3}$ and $\Delta L_{2}=2 \Delta L_{1}=2 \Delta L_{3}$ :

$$
\begin{gathered}
\Delta C=\Delta C_{1}+\frac{D_{1} \Delta L_{2}}{D_{2} \Delta L_{1}} \Delta C_{1}+\frac{D_{1} \Delta L_{3}}{D_{3} \Delta L_{1}} \Delta C_{1}=2\left(1+\frac{D_{1}}{D_{2}}\right) \Delta C_{1} \\
F=D_{1} \frac{\Delta C_{1}}{\Delta L_{1}}=\frac{D_{1} D_{2}}{D_{2}+D_{1}} \frac{\Delta C}{\Delta L_{2}}
\end{gathered}
$$

where the apparent diffusion coefficient $D^{\prime}$ for length $\Delta L_{2}$ of the bound sample is as follows:

$$
F=D^{\prime} \frac{\Delta C}{\Delta L_{2}}=\frac{D_{1} D_{2}}{D_{2}+D_{1}} \frac{\Delta C}{\Delta L_{2}}
$$

Therefore, it becomes the following:

$$
D_{2}=\frac{D_{1} D^{\prime}}{D_{1}-D^{\prime}}
$$

Assuming that the diffusion coefficient for porous stone and glass filters is equivalent to approximately $3 \times 10^{-10} \mathrm{~m}^{2} / \mathrm{s}$, which is the average of the diffusion coefficient for porous stone and glass filters, the relationship between $D_{2}$ and $D^{\prime}$ is shown in Figure 5 . When $D_{1}$ is sufficiently larger than $D^{\prime}\left(D_{1} \gg D^{\prime}\right), D_{2}$ is equivalent to $D^{\prime}\left(D_{2} \fallingdotseq D^{\prime}\right)$. 


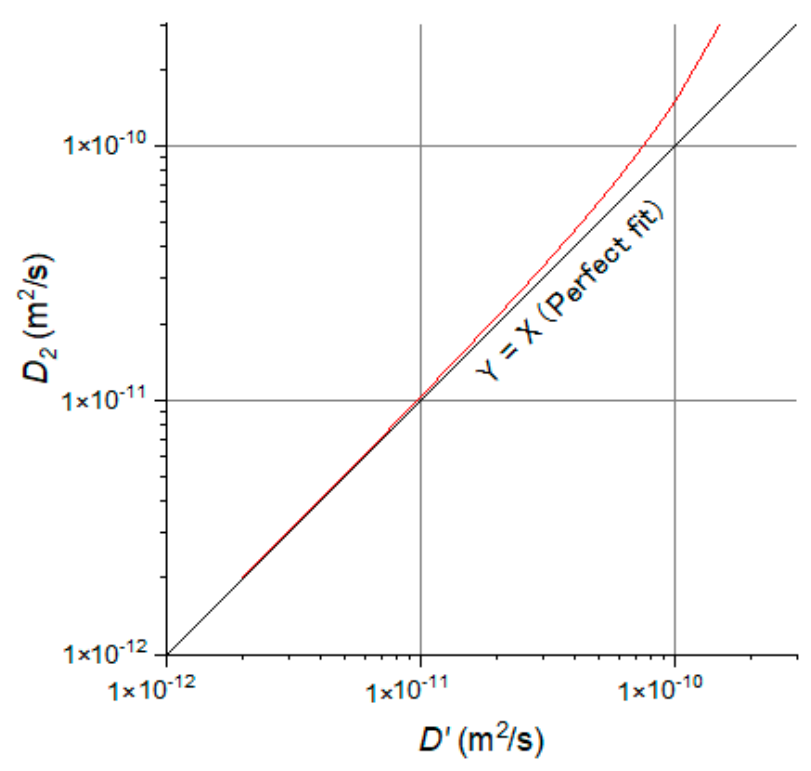

Figure 5. Diffusion coefficient relationship between the bound and target samples. $D^{\prime}$ on $x$-axis and $D_{2}$ on $y$-axis are the effective diffusion coefficients for the bounded samples and target sample, respectively. It is assumed that $D_{1}=D_{3}=3 \times 10^{-10} \mathrm{~m} / \mathrm{s}$ and $L_{2}=2 L_{1}=2 L_{3}$. ${ }^{*} D^{\prime}$ is calculated for the target sample width $\left(L_{2}\right)$, not for the bounded samples $\left(L_{1}+L_{2}+L_{3}\right)$.

To estimate the isotope fractionation, $D_{1}$ and $D_{h}$ are set as the diffusion coefficients for the light and heavy isotopes, respectively. Here, the isotope fractionation factor $\alpha$ is set as $D_{1} / D_{h} . \alpha^{\prime}$ is the isotope fractionation factor of the bounded sample. $\alpha^{\prime}$ can be expressed as follows:

$$
\alpha^{\prime}=\frac{D_{l}^{\prime}}{D_{h}^{\prime}}=\frac{\frac{D_{l 1} D_{l 1}}{D_{l 1}+D_{l 2}}}{\frac{D_{h 1} D_{h 2}}{D_{h 1}+D_{h 2}}}=\frac{D_{l 1} D_{l 2}\left(D_{h 1}+D_{h 2}\right)}{D_{h 1} D_{h 2}\left(D_{L 1}+D_{L 2}\right)}=\alpha_{1} \alpha_{2} \frac{\frac{1}{\alpha_{1}}+\frac{1}{\alpha_{2}} \frac{D_{h 2}}{D_{h 1}}}{1+\frac{D_{l 2}}{D_{l 1}}}
$$

where $D_{h 2} / D_{h 1}$ and $D_{l 2} / D_{l 1}$ are equivalent to $D_{2} / D_{1}$.

As a result, the isotope fractionation factor of $\alpha_{2}$ can be solved as follows:

$$
\alpha_{2}=\alpha^{\prime}+\left(\alpha^{\prime}-\alpha_{1}\right) \frac{D_{2}}{D_{1}}=\alpha^{\prime}+\left(\alpha^{\prime}-\alpha_{1}\right) \frac{D^{\prime}}{D_{1}-D^{\prime}}
$$

Assuming that $D_{1}$ and $\alpha_{1}$ are set to be $3 \times 10^{-10} \mathrm{~m}^{2} / \mathrm{s}$ and 1.0014 , respectively, $\alpha_{2}$ can be calculated by using $D^{\prime}$ and $\alpha^{\prime}$, as shown in Figure 6 . When $D_{1}$ is significantly larger than $D^{\prime}\left(D_{1} \gg D^{\prime}\right), \alpha_{2}$ is equivalent to $\alpha^{\prime}\left(\alpha_{2} \fallingdotseq \alpha^{\prime}\right)$. Therefore, if $D_{1}$ is significantly larger than $D^{\prime}, D^{\prime}$ and $\alpha^{\prime}$ are equivalent to the original value of $D_{2}$ and $\alpha_{2}$.

\subsection{Diffusion Coefficient}

For the artificial samples consisting of ceramic discs, porous stones, and glass filters, the diffusion coefficients of $\mathrm{HDO}$ and $\mathrm{Cl}$ were similar. The diffusion coefficients of $\mathrm{HDO}$ were about 1.0-1.3 times higher than those of $\mathrm{Cl}$.

On the contrary, for natural samples, the diffusion coefficients of HDO were three to four times higher than those of $\mathrm{Cl}$. The differences in diffusion coefficients for natural samples were much higher than those of artificial samples. This may have been related to the influence of the negative charge of surfaces [21]. The diffusion coefficients of $\mathrm{Br}$ were similar to those of $\mathrm{Cl}$. Anions were transported within small areas compared to the water isotopes ( $\mathrm{HDO}$ an $\mathrm{H}_{2}{ }^{18} \mathrm{O}$ ). Thus, the ratio of the diffusion coefficients of HDO and $\mathrm{Cl}$ depends on the clay content and pore properties, including the porosity and tortuosity. Thus, a diffusion experiment was necessary to determine the difference in the diffusion coefficients. 


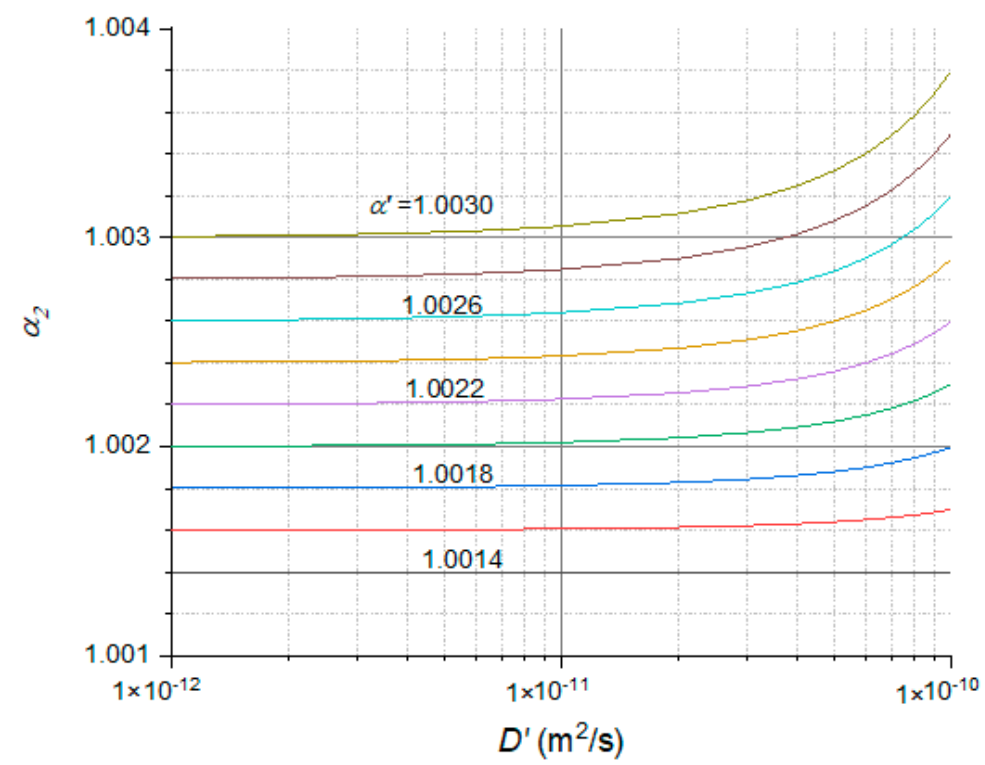

Figure 6. Fractionation factor relationship between bound and target samples. $D^{\prime}$ on $x$-axis and $\alpha^{\prime}$ are the effective diffusion coefficient and fractionation factor for bounded samples, respectively. $\alpha_{2}$ on $y$-axis is the fractionation factor for the target sample. It is assumed that $D_{1}=D_{3}=3 \times 10^{-10} \mathrm{~m} / \mathrm{s}$ and $\alpha_{1}=\alpha_{3}=1.0014$.

The diffusion coefficient of NAP was about one-fifth that of $\mathrm{Cl}$ for artificial samples. In comparison, the diffusion coefficient of natural samples could not be calculated because the NAP concentration in the low-concentration tank was below the analytical detection limit. NAP is organic matter, with a large molecular weight and structure compared to individual ions; thus, it has a very low diffusion coefficient and cannot pass thorough small pores. If organic matter can be transported by advection and not diffusion, the presence of remaining organic matter relative to other ions may be evidence of a diffusion-dominant domain.

The effective porosity is shown in Table 4 . With the exception of the Richmond and Marree samples, there was no significant difference between the effective porosities of $\mathrm{HDO}$ and $\mathrm{Cl}$, and all were within $20 \%$. In contrast, in the Richmond and Marree samples, the effective porosity of $\mathrm{Cl}$ decreased with a decreasing drying porosity. The ratio of the effective porosities of $\mathrm{Cl}$ and $\mathrm{HDO}$ was nearly 1.2. It is possible that the difference in the diffusion coefficient was counteracted by the effective porosity. Thus, measuring the effective porosity is important.

As shown above, the diffusion coefficient of HDO was about three to four times higher than that of $\mathrm{Cl}$, and the difference in the effective porosity between $\mathrm{HDO}$ and $\mathrm{Cl}$ was not significant compared to the difference in diffusion. Therefore, $\mathrm{HDO}$ and $\mathrm{Cl}$ were separated by diffusion for natural samples but separation did not occur for artificial samples.

\subsection{Isotope Fractionation Factor}

To estimate the isotope fractionation factor, it was necessary to correct for the initial influence and concentration change [16]. The initial influence could be negated because sampling was not conducted at the beginning of experiment. At least $3 \mathrm{mg}$ of $\mathrm{Cl}$ and $\mathrm{Br}$ was required to measure these isotopes, so the required volume was too high when the concentration in the solution was low. The effect of concentration change increases with time, so it had to be accounted for. A standard curve was used to correct for this effect [16].

For the through-diffusion experiment, the concentration in the low-concentration tank can be expressed as follows [16], when the initial unsteady state is neglected:

$$
C_{L, t}=\frac{1}{\beta} C_{H, 0}\left[1-\exp \left(-\frac{\beta D A}{V W} t\right)\right]
$$


where $C_{L, t}$ is the concentration at time $t$ in the low-concentration tank, $C_{H, 0}$ is the initial concentration in the high-concentration tank, $\beta$ is the condition of the high-concentration tank, $\beta=1$ when the concentration tank remains constant, $\beta=2$ when the concentration changes (normal condition), $D$ is the diffusion coefficient, $A$ is the sample area, $V$ is the sample volume, $W$ is the sample width, and $t$ is the time, as mentioned before.

Using the above equation, the isotope ratio in the low-concentration tank can be expressed as follows:

$$
R_{L, t}=\frac{C_{h, t}}{C_{l, t}}=R_{H, 0} \frac{\left[1-\exp \left(-\frac{\beta D_{\mathrm{h}} A}{V W} t\right)\right]}{\left[1-\exp \left(-\frac{\beta D_{1} A}{V W} t\right)\right]}=R_{H, 0} \frac{\left[1-\exp \left(-\frac{\beta D_{1} A}{\alpha V W} t\right)\right]}{\left[1-\exp \left(-\frac{\beta D_{1} A}{V W} t\right)\right]}
$$

where $C_{l}, t$ and $C_{h}, t$ are the concentration of light and heavy isotopes at $t$, respectively. $\alpha$ is the fractionation factor $\left(=D_{L} / D_{H}\right)$.

$\alpha$ can be solved as follows:

$$
\alpha=-\frac{V W t}{\beta D_{1} A} \frac{1}{\ln \left\{1-\frac{R_{L, t}}{R_{H, 0}}\left[1-\exp \left(-\frac{\beta D_{1} A}{V W} t\right)\right]\right\}}
$$

Then, the following approximation can be applied:

$$
\frac{R_{L, t}}{R_{H, 0}} \approx \exp \frac{\delta C_{L, t}-\delta C_{H, 0}}{10^{3}}
$$

where $\Delta$ is the isotope ratio, subscripts $L$ and $H$ represent the low- and high-concentration tanks, respectively, and subscripts $t$ and 0 represent the time and time $=0$ (initial condition), respectively.

$\alpha$ was calculated for each measured value. The $\alpha$ values and associated errors are listed in Table 2 as averages and standard deviations for measured values. For a bound sample, $\alpha^{\prime}$ can be calculated by Equation (16) and $\alpha^{\prime}$ can be transformed into $\alpha_{2}$ using Equation (13). Here, $\alpha_{1}$ is assumed to be the average for glass filters and porous stones. After this, the average and standard deviation can be calculated. $\alpha_{2}$ is the fractionation factor of a natural sample.

For artificial samples, the fractionation factor of ${ }^{37} \mathrm{Cl}$ was $1.0016 \pm 0.0007$ for ceramic disks and $1.0015 \pm 0.0001$ for porous stone and glass filters. These values were slightly smaller than that of free water, which is $1.0016-1.0018$ at $21^{\circ} \mathrm{C}$ [17]. The fractionation factor of ${ }^{81} \mathrm{Br}$ was $1.0008 \pm 0.0004$ for ceramic disks and $1.0007 \pm 0.00015$ for porous stone and glass filters. These values were similar to that of free water, which is 1.00064 at $21^{\circ} \mathrm{C}$ [17]. For the modular dynamics simulation, the fractionation factor was $1.0019 \pm 0.0010$ for ${ }^{37} \mathrm{Cl}$ [22] and $1.0008 \pm 0.0002$ for ${ }^{81} \mathrm{Br}$ [23]. The measured fractionation factors for artificial samples were similar to that of free water.

The enrichment factor of ${ }^{81} \mathrm{Br}$, which was $(\varepsilon=(\alpha-1) \times 1000 \%$ o, was half of that of ${ }^{37} \mathrm{Cl}$. This was in agreement with the measured value for free water [17].

For natural samples, the fractionation factor of ${ }^{37} \mathrm{Cl}$ was $10018 \pm 0.00003$ for the Koetoi Formation, $1.0020 \pm 0.00008$ for the Wakkanai Formation, and $1.0020 \pm 0.0001$ for the Richmond and Marree samples. These fractionation factors were higher than that of free water. The fractionation factors for the Wakkanai Formation were higher than those for the Koetoi Formation. Here, the fractionation factors increased with decreasing porosity. However, the fractionation factors for Richmond were smaller than those for Marree, which does not agree with the trend observed in the Koetoi and Wakkanai formations. This may have been due to influence from the variation in the isotope measurements. The fractionation factor of ${ }^{81} \mathrm{Br}$ was $1.0008 \pm 0.00001$ for the Koetoi Formation, $1.0009 \pm$ 0.00001 for the Wakkanai Formation, and $1.0008 \pm 0.0001$ for the Marree and Richmond formations. These values were similar to that of free water and those of artificial samples. The enrichment factors of ${ }^{81} \mathrm{Br}$ were about half of ${ }^{37} \mathrm{Cl}$, which also agreed with the artificial 
samples. There was no significant difference between an artificial and natural sample. The enrichment factor of ${ }^{37} \mathrm{Cl}$ was not as high and the enrichment factor of ${ }^{81} \mathrm{Br}$ did not show a distinct difference.

\section{Summary}

Through-diffusion experiments and effective porosity experiments were conducted to evaluate diffusion-dominant domains. For these experiments, ceramic discs, porous stones, and glass filters were used as artificial samples. For natural samples, the Koetoi and Wakkanai Formations, which are sedimentary rock formations in Horonobe, Japan, and confined layers sampled at Richmond and Marree in the Great Artesian Basin, Australia, were used.

For the through-diffusion experiments, $\mathrm{HDO}$ and $\mathrm{H}_{2}{ }^{18} \mathrm{O}$ as water, $\mathrm{Cl}^{-}, \mathrm{Br}^{-}$and $\mathrm{NO}_{3}{ }^{-}$ as anions, and NAP as organic matter were used as tracers. It was found that for artificial samples, the diffusion coefficients of water isotopes were only slightly higher than those of the anions $\mathrm{Cl}^{-}, \mathrm{Br}^{-}$and $\mathrm{NO}_{3}{ }^{-}$. The fractionation factor of ${ }^{37} \mathrm{Cl}$ calculated for artificial samples was 1.0014-1.0017, which was equivalent to that of free water. On the contrary, for natural samples, the diffusion coefficient of water isotopes was three to five times higher than for the anions. The fractionation factor of ${ }^{37} \mathrm{Cl}$ calculated for natural samples was 1.0018-1.0021, which is higher than that of free water, as well as that of the artificial samples. This indicates that the negative charge at the surface of the natural samples influences the diffusion coefficient and fractionation factor. The fractionation factor of ${ }^{81} \mathrm{Br}$ was 1.007-1.009 for the artificial samples and 1.007-1.0010 for the natural samples. This was similar to the fractionation factor calculated for free water. The enrichment factor of ${ }^{81} \mathrm{Br}$ was almost half that of ${ }^{37} \mathrm{Cl}$.

The effective porosity of HDO was larger than for anions, such as $\mathrm{Cl}^{-}$and $\mathrm{Br}^{-}$. For natural samples, the coefficient ratio of HDO and the anions was much larger than the effective porosity ratio of HDO and the anions. Therefore, HDO and the anions were separated by diffusion for natural samples. In contrast, HDO and the anions were not separated by diffusion for artificial samples because the diffusion coefficient and effective porosities of HDO and the anions were not so different. Isotope fractionation was observed for all samples; thus, the isotopes of $\mathrm{Cl}$ and $\mathrm{Br}$ were fractionated by diffusion. The separation of water isotopes and anions and the isotope fractionation of $\mathrm{Cl}$ and $\mathrm{Br}$ are useful parameters to evaluate whether a domain is diffusion-dominant. An investigation focused on the profile of $\delta \mathrm{D}(\mathrm{HDO}), \mathrm{Cl}, \mathrm{Br}, \delta^{37} \mathrm{Cl}$ and $\delta^{81} \mathrm{Br}$ can play an important role in assessing a diffusion-dominant domain. There are many locations where marine formations have been uplifted and exposed to meteoric water. If this marine formation is in a diffusion-dominant condition, this is a very suitable condition for applying the above method, as seawater and meteoric water have very different $\delta \mathrm{D}(\mathrm{HDO})$ and $\mathrm{Cl}$ values, causing a large diffusion gradient. Through-diffusion experiments to estimate the diffusion coefficient and fractionation factors and effective porosity experiments help to better understand diffusion-dominant domains and diffusion times.

Author Contributions: Conceptualization, T.H.; methodology, T.H. and K.N.; investigation, T.H., K.N. and R.G.; writing—original draft preparation, T.H.; writing—review and editing, R.G. All authors have read and agreed to the published version of the manuscript.

Funding: This study entitled 'Research and development project on high-level radioactive waste disposal in geological formation (Development and Improvement on groundwater flow evaluation technique in rock)' was supported by the Japanese Ministry of Economy, Trade and Industry (METI). This study is cooperation study between the Central Research Institute of Electric Power Industry and Japan Atomic Energy Agency (JAEA).

Institutional Review Board Statement: Not applicable.

Informed Consent Statement: Not applicable.

Data Availability Statement: Not applicable. 
Acknowledgments: We thank T. Tokunaga (University of Tokyo), T. Igarashi (Hokkaido Univ.), S. Takeuchi (Nihon Univ.), T. Yuguchi (Yamagata Univ.), and K. Kashiwaya (Kyoto Univ.) for their advice during this project. The cores of Horonobe were provided by Horonobe Underground Research Center (JAEA). We also thank M. Yoshioka and T. Yamaguchi (Ceres) for experimental support.

Conflicts of Interest: The authors declare no conflict of interest.

\section{References}

1. Mazurek, M.; Alt-Epping, P.; Gimi, T.; Niklaus Waber, H.; Bath, A.; Gimmi, T. OECD Nuclear Energy Agency. In Natural Tracer Profiles across Argillaceous Formations: The CLAYTRAC Project; OECD Nuclear Energy Agency: Paris, France, 2009; 361p.

2. Mazurek, M.; Alt-epping, P.; Bath, A.; Gimmi, T.; Waber, H.N.; Buschaert, S.; De Cannière, P.; De Craen, M.; Gautschi, A.; Savoye, S.; et al. Applied Geochemistry Natural tracer profiles across argillaceous formations. Appl. Geochem. 2011, 26, 1035-1064. [CrossRef]

3. Hendry, M.J.; Solomon, D.K.; Person, M.; Wassenaar, L.I.; Gardner, W.P.; Clark, I.D.; Mayer, K.U.; Kunimaru, T.; Nakata, K.; Hasegawa, T. Can argillaceous formations isolate nuclear waste? Insights from isotopic, noble gas, and geochemical profiles. Geofluids 2015, 15, 381-386. [CrossRef]

4. Mills, R. Self-diffusion in normal and heavy water in the range 1-45 . J. Phys. Chem. 1973, 77, 685-688. [CrossRef]

5. Yuan-Hui, L.; Gregory, S. Diffusion of ions in sea water and in deep-sea sediments. Geochim. Cosmochim. Acta 1974, 38, 703-714. [CrossRef]

6. Rübel, A.P.; Sonntag, C.; Lippmann, J.; Pearson, F.J.; Gautschi, A. Solute transport in formations of very low permeability: Profiles of stable isotope and dissolved noble gas contents of pore water in the Opalinus Clay, Mont Terri, Switzerland. Geochim. Cosmochim. Acta 2002, 66, 1311-1321. [CrossRef]

7. Pearson, F.J.; Arcos, D.; Bath, A.; Boisson, J.Y.; Fernández, A.M.; Gäbler, H.E.; Gaucher, E.; Gautschi, A.; Griffault, L.; Hernán, P.; et al. Mont Terri Project-Geochemistry of Water in the Opalinus Clay Formation at the Mont Terri Rock Laboratory-Reports of the Federal Office of Water and Geology (FOWG); Geology Series No.5; FOWG: Bern-lttigen, Switzerland, 2003; ISBN 3-906723-59-3.

8. De Craen, M.; Wemaere, I.; Labat, S.; Van Geet, M. Geochemical Analyses of Boom Clay Pore Water and Underlying Aquifers in the Essen-1 Borehole; SCK•CEN: Mol, Belgium, 2006.

9. Desaulniers, D.E.; Kaufmann, R.S.; Cherry, J.A.; Bentley, H.W. 37Cl-35Cl variations in a diffusion-controlled groundwater system. Geochim. Cosmochim. Acta 1986, 50, 1757-1764. [CrossRef]

10. Eggenkamp, H.G.M.; Groos, A.F.K. Van Chlorine stable isotopes in carbonatites: Evidence for isotopic heterogeneity in the mantle. Chem. Geol. 1997, 140, 137-143. [CrossRef]

11. Lavastre, V.; Jendrzejewski, N.; Agrinier, P.; Marc Javoy, M.E. Chlorine transfer out of a very low permeability clay sequence (Paris Basin, France). Geochim. Cosmochim. Acta 2005, 69, 4949-4961. [CrossRef]

12. Rebeix, R.; Le Gal La Salle, C.; Jean-Baptiste, P.; Lavastre, V.; Fourré, E.; Bensenouci, F.; Matray, J.M.; Landrein, P.; Shouakar-Stash, O.; Frape, S.K.; et al. Chlorine transport processes through a 2000m aquifer/aquitard system. Mar. Pet. Geol. 2014, 53, 102-116. [CrossRef]

13. Hasegawa, T.; Nakata, K.; Mahara, Y.; Habermehl, M.A.; Oyama, T.; Higashihara, T. Characterization of a diffusion-dominant system using chloride and chlorine isotopes $(36 \mathrm{Cl}, 37 \mathrm{Cl})$ for the confining layer of the Great Artesian Basin, Australia. Geochim. Cosmochim. Acta 2016, 192, 279-294. [CrossRef]

14. Habermehl, M.A. The great artesian basin. J. Geol. Soc. Aust. 1980, 5, 9-38. [CrossRef]

15. Ishii, E.; Sanada, H.; Iwatsuki, T.; Sugita, Y.; Kurikami, H. Mechanical strength of the transition zone at the boundary between opal-A and opal-CT zones in siliceous rocks. Eng. Geol. 2011, 122, 215-221. [CrossRef]

16. Hasegawa, T.; Nakata, K. A measurement method for isotope fractionation of $35 \mathrm{Cl}$ and $37 \mathrm{Cl}$ by a conventional through-diffusion experiment. Chem. Geol. 2018, 483, 247-253. [CrossRef]

17. Eggenkamp, H.G.M.; Coleman, M.L. The effect of aqueous diffusion on the fractionation of chlorine and bromine stable isotopes. Geochim. Cosmochim. Acta 2009, 73, 3539-3548. [CrossRef]

18. Drimmie, R.J.; Shouakar-stash, O.; Drimmie, R.J.; Frape, S.K. Determination of inorganic chlorine stable isotopes by continuous flow isotope ratio mass spectrometry Determination of inorganic chlorine stable isotopes by continuous flow isotope ratio mass spectrometry. Rapid Commun. Mass Spectrom. RCM 2005, 19, 121-127. [CrossRef]

19. Shouakar-Stash, O.; Frape, S.K.; Drimmie, R.J. Determination of Bromine Stable Isotopes Using Continuous-Flow Isotope Ratio Mass Spectrometry. Anal. Chem. 2005, 77, 4027-4033. [CrossRef] [PubMed]

20. Crank, J. The Mathematics of Diffusion; Oxford University Press: Oxford, UK, 1975. [CrossRef]

21. Van Loon, L.R.; Glaus, M.A.; Mu, W. Anion exclusion effects in compacted bentonites: Towards a better understanding of anion diffusion. Appl. Geochem. 2007, 22, 2536-2552. [CrossRef]

22. Bourg, I.C.; Sposito, G. Isotopic fractionation of noble gases by diffusion in liquid water: Molecular dynamics simulations and hydrologic applications. Geochim. Cosmochim. Acta 2008, 72, 2237-2247. [CrossRef]

23. Eggenkamp, H. The Geochemistry of Stable Chlorine and Bromine Isotopes; Springer: Berlin/Heidelberg, Germany, 2014; ISBN 9783642285066 . 